\title{
Preservative Effects of Strobilurin Fungicides on Citrus Storage Diseases and Residue Safety Assessment
}

\author{
Yue-Yi Song ${ }^{1,2,}$, Jian-Shu Chen ${ }^{1,2, \dagger}$, Xiao-Jun Chen ${ }^{1,2}$, Qing-Xia Zhang ${ }^{1,2}$, Li Ren ${ }^{1,2}$, Zhi-Yuan Meng ${ }^{1,2}$, \\ Ya-Jun Ren ${ }^{1,2}$, Ling-Jun Guan ${ }^{1,2}$, Tian-Le Fan ${ }^{1,2}$ \& Dian-Jing Shen ${ }^{1,2}$ \\ ${ }^{1}$ Joint International Research Laboratory of Agriculture \& Agri-Product Safety, Yangzhou University, Yangzhou, \\ Jiangsu, China \\ ${ }^{2}$ School of Horticulture and Plant Protection, Yangzhou University, Yangzhou, Jiangsu, China \\ Correspondence: Xiao-Jun Chen, Joint International Research Laboratory of Agriculture \& Agri-Product Safety, \\ Yangzhou University, Yangzhou, Jiangsu, China. Tel: 86-0898-6677-0005. E-mail: cxj@yzu.edu.cn
}

Received: April 13, $2018 \quad$ Accepted: May 21, $2018 \quad$ Online Published: July 15, 2018

doi:10.5539/jas.v10n8p107 URL: https://doi.org/10.5539/jas.v10n8p107

${ }^{\dagger}$ These authors contributed equally to this work.

\begin{abstract}
Ethofenprox, pyraclostrobine, trifloxystrobin and enestroburin are strobilurin fungicides that can effectively control fungal diseases caused by ascomycetes, zygomycetes, imperfect fungi, etc. With the purpose of guaranteeing the safe use of strobilurin fungicides in the prevention and treatment of citrus diseases, toxicity and control effects of the fungicides on citrus storage diseases and GC-MS (gas chromatography-mass spectrometry) were applied in this study to determine its residual safety. The results indicated that ethofenprox, trifloxystrobin, pyraclostrobine, and enestroburin had excellent inhibitory effects on citrus storage diseases at concentration of $200-400 \mu \mathrm{g} / \mathrm{mL}$. Degradation dynamics of 4 fungicides during the storage period of citrus could be expressed as the first-order kinetics equation. The fungicides could penetrate into flesh through peels slowly. Therefore, the residue content of the fungicide on peels was higher than that in the flesh of the same citrus. After citrus fruits were treated for $90 \mathrm{~d}$, the residues were lower than the maximum residue limits in all the countries, so the citrus were safe. This investigation provided the theoretical guidance and technical support for the quality evaluation of citrus products.
\end{abstract}

Keywords: strobilurin fungicide, preservative effects, citrus storage disease, residue, safety assessment

\section{Introduction}

Citrus is the most widely planted fruit in the world and takes the second place in China (Fan et al., 2010; Liu \& $\mathrm{Wu}, 2014)$. The citrus fruit may be infected with different kinds of fungi during storage, which leads to the serious fruit decay and causes economic loss of $20 \%-30 \%$ per year, or even $50 \%$ sometimes (Liu \& Wu, 2014). Particularly, it can be infected by more than 10 kinds of microbes, such as Penicillium italicum Sacc and $P$. digitatum Wehmer which are largely responsible for $70 \%-80 \%$ fruit decay (Liu \& Wu, 2014). Serious losses occur after harvest during marketing and storage of citrus fruit mainly due to green mold caused by $P$. digitatum, followed by blue mold and sourrot respectively caused by P. italicum and Geotrichum candidum (Sholberg et al., 2005; Ma et al., 2015). Inhibiting the infection and proliferation of $P$. italicum and $P$. digitatum is of great importance, through which we can reduce the unnecessary loss of harvested citrus. The biological control has been reported to be effective. Nevertheless, the control of plant diseases is mainly dependent on chemical fungicides (Russell, 2005). Toxic chemical fungicides are massively used to control postharvest storage losses. Postharvest green and blue molds of citrus are controlled by sodium bicarbonate, imazalil, thiabendazole, pyrimethanil and fludioxonil (Adaskaveg et al., 2004; Kanetis et al., 2007; Liu et al., 2007, 2014; Ma et al., 2015). Chemical control of these pathogens on a commercial scale is mainly based on postharvest treatments with strobilurin fungicides, which are the solely registered fungicides applied legally to citrus fruits in the European Union (Kanetis et al., 2007, 2008).

Strobilurin fungicide performance against $P$. digitatum has been widely explored (Balba, 2007). Specifically, strobilurin fungicide has a broad spectrum of activity and can be used against fungal pathogens effectively which 
is a synthetic analogue of fungal metabolites of strobilurins and oudemansins (Bartlett et al., 2002; Balba, 2007; BASF Corporation, 2008; Lu et al., 2015; Xie et al., 2015). Strobilurin fungicides such as ethofenprox, pyraclostrobine, trifloxystrobin and enestroburin are bactericides, but they can also control fungal diseases caused by ascomycetes, zygomycetes and imperfect fungi with protection, treatment, eradication, penetration and absorption activities effectively (Kanetis et al., 2004, 2007, 2008). Compared with commonly used fungicides, strobilurin fungicides including ethofenprox, trifloxystrobin, pyraclostrobine and enestroburin have wider bactericidal spectrum, higher bactericidal activity and the mechanism of action is unique. Strobilurin fungicides can be quickly degraded in plants, soils and water. Moreover, they are environmentally friendly and can effectively protect a variety of crops from diseases. So, strobilurin fungicides have been intensively adopted by many countries such as America and Brazil to control the diseases of citrus or other diseases (OChoa-Acuna et al., 2009; Mahoney \& Gillard, 2014; Benelli et al., 2016; Debona et al., 2016a, 2016b; Woodward et al., 2016). The residue levels and degradation pattern of strobilurin fungicide on various horticultural crops were widely investigated (Marin et al., 2003; Wang et al., 2014; Xue et al., 2014; You et al., 2015; Campillo et al., 2015; Raina-Fulton, 2015; Wu et al., 2016; Li et al., 2016; Guo et al., 2017; Kolosova et al., 2017; Zhao et al., 2017). However, the levels, dose and effectiveness of strobilurin fungicide used in postharvest treatments for citrus fruit were seldom explored in terms of controlling decay. In this paper, we explored the effects of ethofenprox, pyraclostrobine, trifloxystrobin and enestroburin on the prevention and control of the fungus $P$. italicum and $P$. digitatum of citrus as well as the inhibition effects along with residue safety assessment during citrus storage. The study provided the theoretical basis and technical support for the quality and safety inspection of Chinese citrus and other agricultural products.

\section{Materials and Methods}

\subsection{Reagents and Materials}

The fungus $P$. italicum and $P$. digitatum were obtained from China General Microbiological Culture Collection Center.

Citrus were harvested on April 212017 in an experimental orchard under standard horticultural practices in Zhaoqing City, Guangdong Province, China. Citrus were randomly harvested from 10 trees. The fruits were picked from the outer edge of the canopy of each tree, placed in plastic boxes, delivered to the laboratory immediately after harvest, graded, sized, returned to the boxes (40 fruits individually numbered per box), and grouped into eight treatments (each treatment containing nine fruit boxes).

\subsection{Inhibition Effects of the Fungicides on P. digitatum and P. italicum of Citrus}

The antifungal activities of different fungicides on citrus against P.digitatum and P.italicum were determined by mycelial growth assays (Liu et al., 2007). The antifungal activities were determined in vitro by transferring plugs ( $5 \mathrm{~mm}$ in diameter) of mycelium from the leading edge of an actively growing colony to a series of PDA (potato dextrose agar) plates containing 0.5, 1.0, 2.0, 4.0 and $8.0 \mu \mathrm{g} / \mathrm{mL}$ fungicides. Added with distilled water, PDA plates were used as the control. For each concentration, three replicates were arranged. The diameters (minus the diameter of the inoculation plug) of the colonies were measured in 7 days after incubation at $28^{\circ} \mathrm{C}$ in darkness. The median effective concentration of the fungicides $\left(\mathrm{EC}_{50}\right)$ for the isolates were calculated based on linear regression of colony diameter on log-transformed fungicide concentration. The experiment was performed in three replicates. The growth inhibition rates of fungicides against $P$. digitatum and $P$. italicum are calculated as:

$$
\text { Inhibition rate }(\%)=\frac{\text { Colony diameter of control }- \text { Colony diameter of treatment }}{\text { Colony diameter of control }-0.5} \times 100 \%
$$

\subsection{Control Effects of the Fungicides on Citrus Storage Diseases}

Dip treatments were performed according to the method described by Schirra et al. (2002). The experiments were carried out with freshly harvested citrus. Fruits were submerged in the commercial fungicide solution $(5 \%$ of ethofenprox, trifloxystrobin, pyraclostrobine and enestroburin) for $5 \mathrm{~min}$ and then washed by tap water and naturally dried. Fruits were punctured to generate the wounds (approximately $5 \mathrm{~mm}$ in depth) with a nail at four sites around the equator. Fungal strains used in these experiments were $P$. digitatum and $P$. italicum. Inoculums contained conidia $\left(10^{4}\right.$ conidia $\left./ \mathrm{mL}\right)$ and antifungal compounds (strobilurin fungicide, at desired final concentrations). $10 \mu \mathrm{L}$ of the inoculum were applied onto each wound. For each treatment, three replicates (five fruits per replicate and four wounds per fruit) were prepared in each experiment. Then the treated fruits were stored at $20^{\circ} \mathrm{C}$ under the relative humidity of $90 \%$. Symptoms were recorded at different days post-inoculation (dpi) as the number of infected wounds in each replicate. The percentage of infected wounds and mean values for each treatment were calculated as: 


$$
\begin{gathered}
\text { Rotten fruit rate }(\%)=\frac{\text { Rotten fruit number }}{\text { Total fruit number }} \times 100 \% \\
\text { Control efficiency }(\%)=\frac{\text { Rotten fruit rate of control - Rotten fruit rate of treatment }}{\text { Rotten fruit rate of control }} \times 100 \%
\end{gathered}
$$

\subsection{Extraction, Clean-Up Procedures and Detection of the Fungicides From Citrus Samples}

\subsubsection{Preparation of Standard Solutions}

Standard solutions were prepared as follows. The stock solutions of the fungicides were diluted by adding hexane to obtain the following final concentrations: $0.05,0.1,0.2,0.4$ and $0.8 \mu \mathrm{g} / \mathrm{mL}$. All standard solutions were stored at $4{ }^{\circ} \mathrm{C}$ before using. The concentrations of the fungicide samples were determined by GC-MS. About $1.0 \mu \mathrm{L}$ of aliquots were injected directly into the GC-MS system. Quantifications of strobilurin fungicide (ethofenprox, trifloxystrobin, pyraclostrobine and enestroburin) were based on the external standard method.

\subsection{Extraction, Clean-Up Procedures of the Fungicide Residues From Citrus Samples}

To investigate the efficiency of extraction and clean-up procedures, recovery experiments were carried out at different levels to establish the reliability and validity of the analytical method. Fruit samples were weighed and peeled. The peel was weighed and its percentage with respect to the whole fruit weight was calculated. The peel was then minced with a mincing knife and was homogenized. The samples were stored in a freezer at $-20{ }^{\circ} \mathrm{C}$ until analysis. Citrus samples $(20 \mathrm{~g})$ were homogenized in $30 \mathrm{~mL}$ of acetonitrile with a high-speed homogenizer for $3 \mathrm{~min}$. In recovery experiments, ethofenprox, trifloxystrobin, pyraclostrobine and enestroburin were added to the samples respectively. The three final concentration of ethofenprox was $0.005,0.5$ and $1.0 \mu \mathrm{g} / \mathrm{g}$, so was that of trifloxystrobin. The three final concentration of pyraclostrobine was $0.01,0.5$ and $1.0 \mu \mathrm{g} / \mathrm{g}$, so was that of enestroburin. A blank control group was also arranged and all the experiments were repeated three times. Ethofenprox, trifloxystrobin, pyraclostrobine and enestroburin were extracted from citrus samples according to QuEChERS method after different cleaning treatments (Anastassiades et al., 2003; Schenck \& Hobb, 2004). PSA (Primary secondary amine) $(150 \mathrm{mg})$ and anhydrous magnesium sulfate $(6 \mathrm{~g})$ were added to the samples before centrifuging at $4000 \mathrm{rpm}$ for $5 \mathrm{~min}$. About $20 \mathrm{~mL}$ of the supernatant was collected and added into the centrifuge tubes containing $\mathrm{Na}_{2} \mathrm{SO}_{4}$. The supernatant was evaporated to near dryness with a vacuum rotary evaporator at $45^{\circ} \mathrm{C}$ and to dry under a gentle nitrogen stream. The residue was redissolved in $1 \mathrm{~mL}$ of acetonitrile for clean-up.

TPH SPE sorbent column was activated with $10 \mathrm{~mL}$ of acetonitrile-toluene $(\mathrm{V} / \mathrm{V}=3 / 1)$ solutions and the sample extracts were loaded onto the SPE tubes. Then the SPE column was washed by $10 \mathrm{~mL}$ of acetonitrile-toluene $(\mathrm{V} / \mathrm{V}=3 / 1)$ solutions. Finally, the elution was collected in the conical vial and the obtained elution was evaporated to near dryness with a vacuum rotary evaporator at $45{ }^{\circ} \mathrm{C}$ and to dryness under a gentle nitrogen stream. The residue was redissolved in $1 \mathrm{~mL}$ of hexane prior to the GC-MS analysis.

\subsection{Detection Method of the Fungicides From the Citrus Samples}

The optimal operating parameters of GC-MS analysis were as follows. A Agilent Technologies Model GC 7890 series gas chromatograph coupled with an Agilent 5975 series mass-selective detector quadrupole mass spectrometer (Agilent Technologies, CA, USA) was employed for all analyses. Samples were separated on HP-5 MS capillary column. The oven temperature was initially maintained at $160{ }^{\circ} \mathrm{C}$ for $1 \mathrm{~min}$ and the temperature was raised to $280^{\circ} \mathrm{C}$ at a rate of $15 / \mathrm{min}$ followed by isothermal period of $4 \mathrm{~min}$. Then the temperature was raised to $300{ }^{\circ} \mathrm{C}$ at a rate of $10{ }^{\circ} \mathrm{C} / \mathrm{min}$ followed by isothermal period of $4 \mathrm{~min}$. The injector was heated to $280{ }^{\circ} \mathrm{C}$ and operated in the splitless mode and the injection volume was $1.0 \mu \mathrm{L}$. Ionization methods was $\mathrm{EI}^{+}$and the quadrupole temperature was $150{ }^{\circ} \mathrm{C}$. Ion source temperature was $230{ }^{\circ} \mathrm{C}$ and the detection mode was the selective ion mode. The carrier gas was helium at a flow rate of $1.0 \mathrm{~mL} / \mathrm{min}$.

\subsection{Degradation Dynamics of the Fungicides in the Citrus}

After the fruits were treated with the fungicides, 5 citrus were collected from randomly selected sampling points at different time. Each citrus was divided into two parts: peel and flesh. Then the samples were mixed according to the quadrant sampling method. Finally, the samples were extracted, purified and analyzed according to the method described above.

\subsection{Statistical Analysis}

All statistical analyses were performed by the GraphPad InStat software and Statistica 8.0 software. The 95\% significance level was adopted for all comparisons. The $\mathrm{EC}_{50}$ and $95 \%$ confidence limits were estimated by Probit analysis. 


\section{Results and Discussion}

\subsection{Antifungal Activity Assays of the Fungicides Against P. digitatum and P. italicum of Citrus}

The $\mathrm{EC}_{50}$ values of the $P$. digitatum exposed to ethofenprox, trifloxystrobin, pyraclostrobine and enestroburin were respectively $1.74,4.54,6.95$ and $5.26 \mu \mathrm{g} / \mathrm{mL}$ at $24 \mathrm{~h}$ (Table 1). The $\mathrm{EC}_{50}$ values of the $P$. italicum exposed to ethofenprox, trifloxystrobin, pyraclostrobine and enestroburin were $3.43,2.01,3.54$ and $4.76 \mu \mathrm{g} / \mathrm{mL}$ at $24 \mathrm{~h}$ respectively. The $\mathrm{EC}_{50}$ value of the P.italicum exposed to prochloraz at $24 \mathrm{~h}$ was $5.28 \mu \mathrm{g} / \mathrm{mL}$, which was below that of strobilurin fungicide (Table 2).

Table 1. Inhibition effects of strobilurin fungicides against citrus $P$. digitatum

\begin{tabular}{lllll}
\hline Fungicides & Toxicity regression equations & $\mathrm{EC}_{50}$ values $(\mu \mathrm{g} / \mathrm{mL})$ & Correlation coefficients & Confidence intervals $(95 \%)$ \\
\hline Ethofenprox & $\mathrm{y}=4.8279+0.7125 \mathrm{x}$ & 1.74 & 0.9601 & $0.54-5.61$ \\
Trifloxystrobin & $\mathrm{y}=4.3311+1.0185 \mathrm{x}$ & 4.54 & 0.9921 & $2.57-8.02$ \\
Pyraclostrobine & $\mathrm{y}=3.9488+1.2484 \mathrm{x}$ & 6.95 & 0.9759 & $4.72-10.24$ \\
Enestroburin & $\mathrm{y}=4.3906+0.8455 \mathrm{x}$ & 5.26 & 0.9718 & $2.85-9.09$ \\
Prochloraz & $\mathrm{y}=4.6401+0.5788 \mathrm{x}$ & 4.20 & 0.9865 & $1.61-10.97$ \\
Imazalil & $\mathrm{y}=4.3631+1.0866 \mathrm{x}$ & 3.86 & 0.9813 & $2.11-7.09$ \\
\hline
\end{tabular}

Table 2. Inhibition effects of the fungicides against citrus $P$. italicum

\begin{tabular}{lllll}
\hline Fungicides & Toxicity regression equations & $\mathrm{EC}_{50}$ values $(\mu \mathrm{g} / \mathrm{mL})$ & Correlation coefficients & Confidence intervals $(95 \%)$ \\
\hline Ethofenprox & $\mathrm{y}=4.0194+1.8132 \mathrm{x}$ & 3.43 & 0.9973 & $2.16-5.44$ \\
Trifloxystrobin & $\mathrm{y}=4.7052+0.9743 \mathrm{x}$ & 2.01 & 0.9520 & $0.84-4.82$ \\
Pyraclostrobine & $\mathrm{y}=4.5192+0.8758 \mathrm{x}$ & 3.54 & 0.9852 & $1.69-7.39$ \\
Enestroburin & $\mathrm{y}=4.3793+0.9163 \mathrm{x}$ & 4.76 & 0.9936 & $2.59-8.75$ \\
Prochloraz & $\mathrm{y}=4.2942+0.9769 \mathrm{x}$ & 5.28 & 0.9875 & $3.06-9.11$ \\
Imazalil & $\mathrm{y}=4.7329+1.0685 \mathrm{x}$ & 1.78 & 0.9908 & $0.71-4.44$ \\
\hline
\end{tabular}

\subsection{Control Effects of the Fungicides Against Storage Diseases of Citrus}

The rates of rotten fruits between 30-d storage and 90-d storage showed no significant differences after the citrus were treated with ethofenprox, trifloxystrobin, pyraclostrobine and enestroburin at concentrations $200 \mu \mathrm{g} / \mathrm{mL}$ and $400 \mu \mathrm{g} / \mathrm{mL}$ for $90 \mathrm{~d}$ (Figure 1). The results indicated that ethofenprox, trifloxystrobin, pyraclostrobine and enestroburin within the concentration range of $200-400 \mu \mathrm{g} / \mathrm{mL}$ had the good control effect on citrus storage diseases.

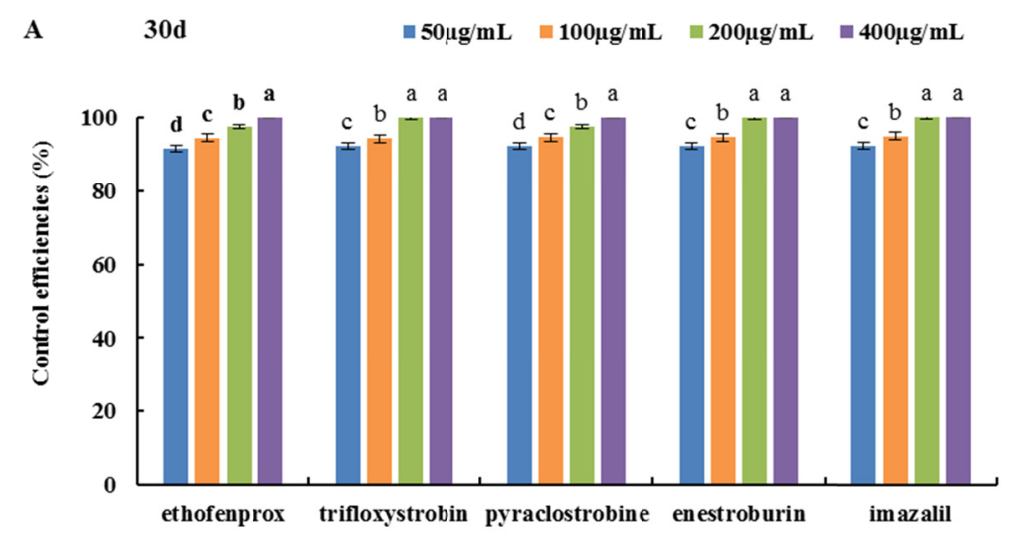



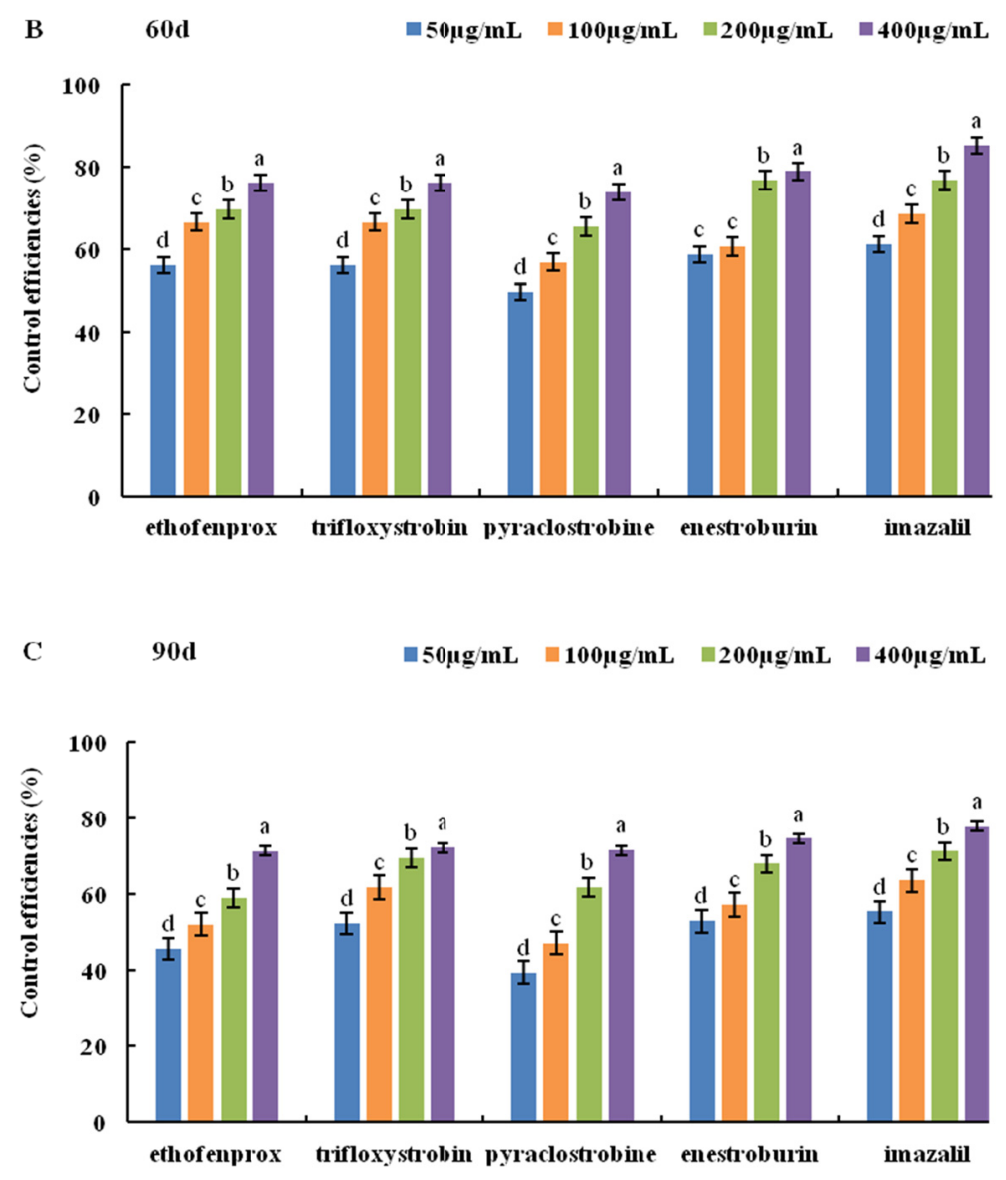

Figure 1. Control effects of the fungicides on citrus storage diseases

\subsection{Fortified Recoveries and Precision of the Fungicides From the Citrus Samples}

Under the selected experimental conditions, the total ion chromatogram of ethofenprox, trifloxystrobin, pyraclostrobine and enestroburin were obtained. The observed mass transitions and the collision energy used for quantitation of ethofenprox, trifloxystrobin, pyraclostrobine and enestroburin were shown in Table 3. Parent compound of the four Strobilurin fungicides were subjected to collision-induced dissociation in the MRM positive mode. Chromatographic separation of strobilurin fungicides were conducted using temperature-programmed route, with retention times of $7.739 \mathrm{~min}$ for ethofenprox, $8.150 \mathrm{~min}$ for trifloxystrobin, $10.097 \mathrm{~min}$ for pyraclostrobine, and $13.991 \mathrm{~min}$ for enestroburin (Figure 2).

Table 3. Quantitative and qualitative ions of the fungicides

\begin{tabular}{llllll}
\hline Fungicides & Retention time & Quantitative ions & Qualitative ions I & Qualitative ions II & Qualitative ions III \\
\hline Ethofenprox & 7.739 & 206 & 131 & 116 & 313 \\
Trifloxystrobin & 8.150 & 131 & 116 & 172 & 377 \\
Pyraclostrobine & 10.097 & 325 & 132 & 133 & 146 \\
Enestroburin & 13.991 & 205 & 189 & 145 & 146 \\
\hline
\end{tabular}




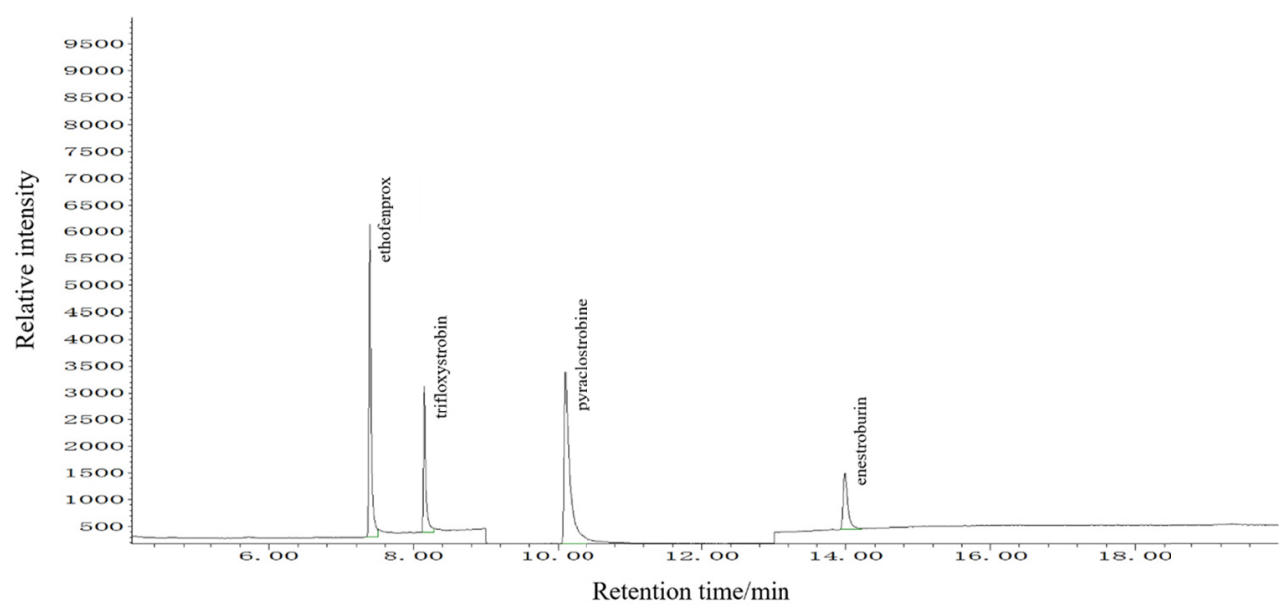

Figure 2. GC-MS chromatogram of ethofenprox, trifloxystrobin, pyraclostrobine, and enestroburin standards

The average recovery was above $80 \%$ and the coefficients of variation were respectively $4.20 \%-7.09 \%$, $6.15 \%-6.78 \%, 2.77 \%-5.90 \%$ and $2.49 \%-4.81 \%$, which met the requirements of pesticide residue analysis (Table 4). The average recoveries and coefficients of variance were within the range required for residue analysis (Commission, 2007). Based on the noise signal of GC-MS, the lower limits of detection of ethofenprox, trifloxystrobin, pyraclostrobine and enestroburin were $0.005,0.005,0.01$ and $0.01 \mathrm{mg} / \mathrm{kg}$, respectively (Table 5). GC-MS chromatograms of different samples were shown in Figures 3-4.

Table 4. Fortified recoveries and precisions of the fungicides in citrus samples $(n=10)$

\begin{tabular}{lllll}
\hline Fungicides & Fortification levels $(\mathrm{mg} / \mathrm{kg})$ & Average recovery rates $(\%)$ & Standard deviations & Coefficients of variation $(\%)$ \\
\hline Ethofenprox & 0.005 & 87.68 & 0.0002 & 4.33 \\
& 0.5 & 90.04 & 0.0189 & 4.20 \\
\hline Trifloxystrobin & 0.005 & 88.10 & 0.0625 & 7.09 \\
& 0.5 & 92.55 & 0.0003 & 6.45 \\
\hline Enestroburin & 1.0 & 95.32 & 0.0293 & 6.15 \\
& 0.01 & 92.72 & 0.0629 & 6.78 \\
\hline Pyraclostrobine & 0.5 & 86.64 & 0.0003 & 3.24 \\
& 0.01 & 92.74 & 0.0275 & 5.90 \\
& 0.5 & 89.35 & 0.0248 & 2.77 \\
\hline & 1.0 & 87.72 & 0.0003 & 3.65 \\
\hline
\end{tabular}

Table 5. Lower limits of detection of the fungicides in citrus by GC-MS

\begin{tabular}{llll}
\hline Fungicides & Linear range $(\mathrm{mg} / \mathrm{kg})$ & Correlation coefficients & Lower limits of detection $(\mathrm{mg} / \mathrm{kg})$ \\
\hline ethofenprox & $0.05-0.8$ & 0.9997 & 0.005 \\
trifloxystrobin & $0.05-0.8$ & 0.9999 & 0.005 \\
pyraclostrobine & $0.05-0.8$ & 0.9989 & 0.01 \\
enestroburin & $0.05-0.8$ & 0.9980 & 0.01 \\
\hline
\end{tabular}




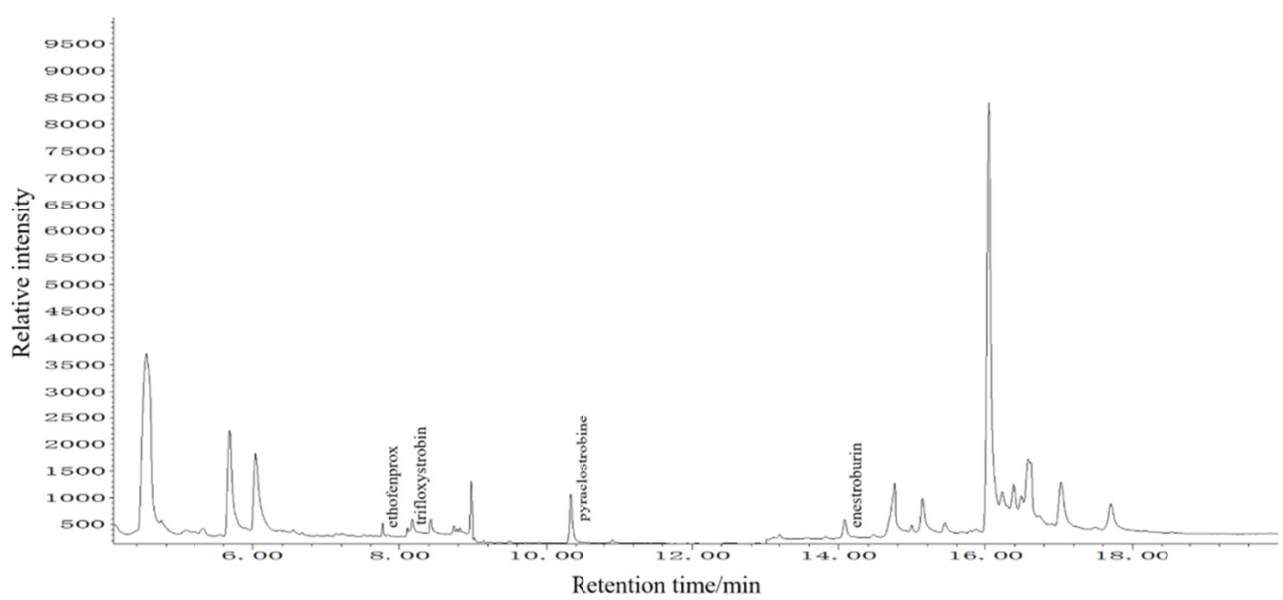

Figure 3. GC-MS chromatogram of blank citrus sample

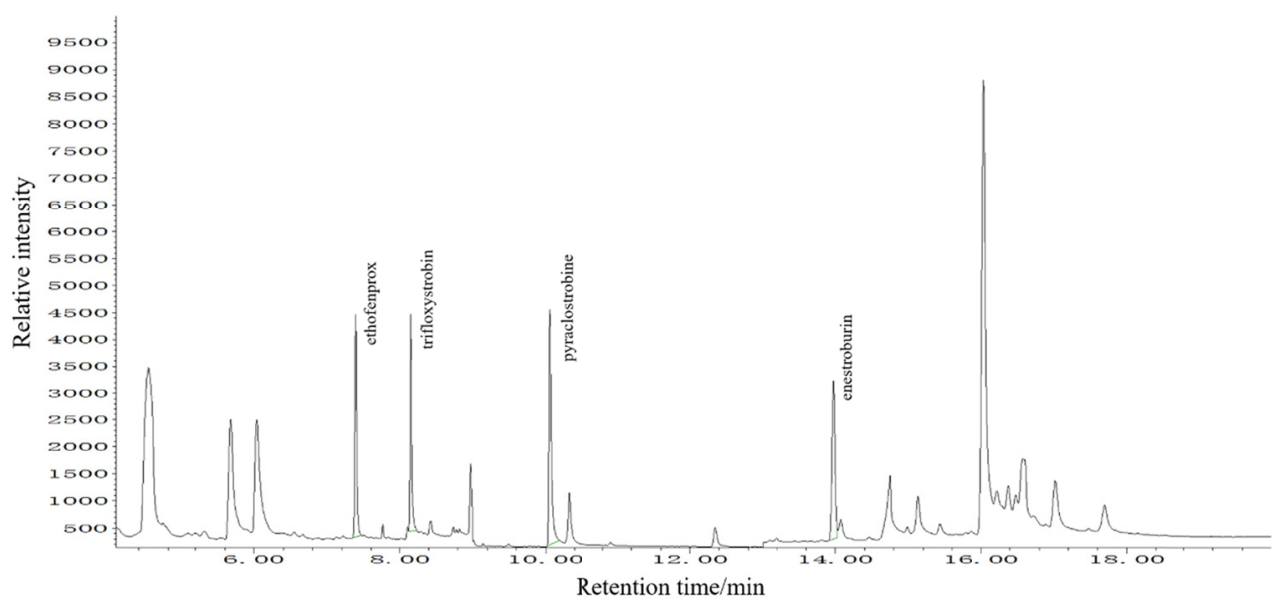

Figure 4. GC-MS chromatogram of citrus sample

\subsection{Residues of the Fungicides in the Citrus After Different Storage Time}

\subsubsection{Residual Dynamics of the Fungicides in Citrus}

The results indicated that the degradation dynamic equations of ethofenprox, trifloxystrobin, pyraclostrobine and enestroburin in the citrus could be expressed as the first-order reaction dynamic equations. The half-lives of the four Strobilurin fungicides in the citrus peels were respectively 14.56, 10.85, 22.87 and $16.50 \mathrm{~d}$. The half-lives of them in the citrus flesh were 12.74, 9.39, 20.09 and $13.00 \mathrm{~d}$, respectively (Table 6). The half-lives of four fungicides in the citrus were all less than $30 \mathrm{~d}$, indicating that the four fungicides were degradable low-residue fungicides.

Table 6. Degradation kinetic parameters of the fungicides during citrus storage

\begin{tabular}{llllll}
\hline Fungicides & Citrus parts & Degradation kinetics equations & Velocity constants $(K)$ & Correlation coefficients $(\mathrm{r})$ & Half-lives $(\mathrm{d})$ \\
\hline \multirow{2}{*}{ ethofenprox } & peel & $C_{t}=1.7025 \mathrm{e}^{-0.0476 \mathrm{t}}$ & 0.0476 & 0.9870 & 14.56 \\
& flesh & $C_{t}=0.1584 \mathrm{e}^{-0.0544 \mathrm{t}}$ & 0.0544 & 0.9433 & 12.74 \\
\multirow{3}{*}{ trifloxystrobin } & peel & $C_{t}=1.4345 \mathrm{e}^{-0.0639 \mathrm{t}}$ & 0.0639 & 0.9978 & 10.85 \\
& flesh & $C_{t}=0.1223 \mathrm{e}^{-0.0738 \mathrm{t}}$ & 0.0738 & 0.9522 & 9.39 \\
\multirow{5}{*}{ pyraclostrobine } & peel & $C_{t}=1.4739 \mathrm{e}^{-0.0303 t}$ & 0.0303 & 0.9979 & 22.87 \\
& flesh & $C_{t}=0.1141 \mathrm{e}^{-0.0345 t}$ & 0.0345 & 0.9252 & 20.09 \\
\multirow{2}{*}{ enestroburin } & peel & $C_{t}=1.1955 \mathrm{e}^{-0.0420 \mathrm{t}}$ & 0.0420 & 0.9938 & 16.50 \\
& flesh & $C_{t}=0.0880 \mathrm{e}^{-0.0533 t}$ & 0.0533 & 0.9793 & 13.00 \\
\hline
\end{tabular}




\subsection{Residues of the Fungicides in Citrus Peels and Fruit Flesh After Different Storage Times}

The terminal residue of trifloxystrobin in the citrus peels was less than $0.3 \mathrm{mg} / \mathrm{kg}$ after the citrus were treated with trifloxystrobin WDG $(50 \%)$ at concentrations of $400 \mu \mathrm{g} / \mathrm{mL}$ for $30 \mathrm{~d}$. The terminal residue of pyraclostrobine in the citrus peels was $0.13 \mathrm{mg} / \mathrm{kg}$ after the citrus were treated by pyraclostrobin EC $(250 \mathrm{~g} / \mathrm{L})$ at the concentration of $400 \mu \mathrm{g} / \mathrm{mL}$ for $90 \mathrm{~d}$ (Table 7). The terminal residues of four kinds of fungicides in the citrus fruit flesh were lower than those in the peels after the citrus fruits were treated with four fungicides at the concentration of $400 \mu \mathrm{g} / \mathrm{mL}$ for 30,60 and $90 \mathrm{~d}$ (Table 8).

Table 7. Residues of the fungicides in citrus fruit peels after different storage times

\begin{tabular}{llcc}
\hline \multirow{2}{*}{ Fungicides } & \multicolumn{3}{l}{ Residues of fungicides in citrus fruit peels after different storage time $(\mathrm{mg} / \mathrm{kg})$} \\
\cline { 2 - 4 } & $30 \mathrm{~d}$ & $60 \mathrm{~d}$ & $90 \mathrm{~d}$ \\
\hline Ethofenprox & 0.44 & 0.20 & 0.11 \\
Trifloxystrobin & 0.23 & 0.07 & 0.03 \\
Pyraclostrobine & 0.58 & 0.22 & 0.13 \\
Enestroburin & 0.41 & 0.09 & 0.04 \\
\hline
\end{tabular}

Table 8. Residues of the fungicides in citrus fruit flesh after different storage times

\begin{tabular}{llll}
\hline \multirow{2}{*}{ Fungicides } & \multicolumn{3}{l}{ Residues of fungicides in citrus fruit flesh after different storage time $(\mathrm{mg} / \mathrm{kg})$} \\
\cline { 2 - 4 } & $30 \mathrm{~d}$ & $60 \mathrm{~d}$ & $90 \mathrm{~d}$ \\
\hline Ethofenprox & 0.041 & 0.014 & 0.01 \\
Trifloxystrobin & 0.027 & 0.011 & 0.006 \\
Pyraclostrobine & 0.041 & 0.027 & 0.016 \\
Enestroburin & 0.023 & 0.011 & $\mathrm{ND}$ \\
\hline
\end{tabular}

Strobilurin fungicides such as ethofenprox, trifloxystrobin, pyraclostrobine and enestroburin had different inhibition effects on the $P$. italicum and $P$. digitatum. In recent years, fungicides still play an important role in pest management and the substitutes are still not found. The baseline sensitivities of $P$. digitatum populations to novel fungicides from different chemical classes such as azoxystrobin, fludioxonil and pyrimethanil were established by Kanetis et al. (2004). Investigations on strobilurin fungicide in postinoculation treatments on pear (Pyrus communis L.) showed that the new "low-risk" fungicides such as fenhexamid, fludioxonil and strobilurin fungicide had high activity against the gray mold caused by Botrytis cinerea, while blue mold caused by Pyrus expansum can beeffectively controlled only by fludioxonil and strobilurin fungicide (Adaskaveg \& Forster, 2004). In preinoculation treatments, fenhexamid effectively controlled gray mold, nevertheless, strobilurin fungicide effectively controlled blue mold. Sholberg et al. (2005) indicated that pre- or post-harvest applications of strobilurin fungicide could control gray and blue mold on stored apples effectively. Especially at $50{ }^{\circ} \mathrm{C}$, postharvest treatments with strobilurin fungicide can effectively control green and blue mold in citrus. The maximum residue limits of ethofenprox, trifloxystrobin and pyraclostrobine show differences in different countries. In the European Union, the maximum residue of trifloxystrobin and pyraclostrobine on fruits like citrus were 0.3 and $1 \mathrm{mg} / \mathrm{kg}$ (CAC, 2016; European Commission, 2016; GB2763-2016, 2017). In Japan, the maximum residue of ethofenprox, trifloxystrobin and pyraclostrobine are $1,0.3$, and $10 \mathrm{mg} / \mathrm{kg}$, respectively. Therefore, it is essential to regulate the applied doses of the fungicides to remove the barrier of international trade and make the pulp processing safe. In this study, after the leaching treatment with $400 \mu \mathrm{g} / \mathrm{mL}$ ethofenprox, trifloxystrobin, pyraclostrobine and enestroburin, the residue of fungicides in the whole storage process was lower than $0.3 \mathrm{mg} / \mathrm{kg}$, which was below the maximum residue limit. Degradation dynamics of 4 fungicides during the citrus storage period was proposed on the basis of the first-order kinetics equation. As a result, strobilurin fungicides could penetrate into flesh through the peels and the residues in the peels were higher than that in the flesh in the same citrus. After being treated for $3 \mathrm{~d}$, the residues in the citrus were lower than the maximum residue limits required in European Union and Japan. The residues in the citrus were lower than the maximum residues in other countries and the treated citrus were safe fruits after the citrus were treated for $90 \mathrm{~d}$.

\section{Conclusions}

This study revealed that ethofenprox, trifloxystrobin, pyraclostrobine and enestroburin could efficiently control the storage diseases of citrus at the concentration of $200-400 \mu \mathrm{g} / \mathrm{mL}$. The fungicides could penetrate into flesh 
through the peels when the citrus were treated with strobilurin fungicide and the residues of the peels were higher than that of the flesh in the same citrus. After the citrus were treated for $90 \mathrm{~d}$, the residue level in the citrus was lower than the maximum residue limits specified in different countries and the citrus were safe.

\section{Acknowledgements}

We gratefully acknowledge the financial support received from Key Research and Development Program of Jiangsu Province (BE2017344, BE2015354), Six Talent Peaks Project in Jiangsu Province (NY-101), Practicality and Innovation Training Project for Undergraduate Students in Jiangsu Province (201611117053Y) and Science and Technology Plan Project of Hanjiang District (2016).

\section{References}

Adaskaveg, J. E., \& Forster, H. (2004). New reduced-risk postharvest fungicides for management of gray and blue molds of pears and their use in fungicide resistance management. Phytopathology, 94, S149.

Anastassiades, M., Lehotay, S. J., Stajnbaher, D., \& Schenck, F. J. (2003). Fast and easy multiresidue method employing acetonitrile extraction/partitioning and "dispersive solid-phase extraction" for the determination of pesticide residues in produce. Journal of AOAC International, 86(2), 412-431.

Balba, H. (2007). Review of strobilurin fungicide chemicals. Journal of Environmental Science and Health Part, $B, 42,441-451$. https://doi.org/10.1080/03601230701316465

Bartlett, D. W., Clough, J. M., Godwin, J. R., Hall, A. A., Hamer, M., \& Parr-Dobrzanski, B. (2002). The strobilurin fungicides. Pest Management Science, 58, 649-662. https://doi.org/10.1002/ps.520

BASF Corporation. (2008). Headline fungicide supplemental label. NVA 2008-04-088-0327. Research Triangle Park, NC. Ecotoxicology and Environmental Safety, 7, 423-434.

Benelli, J. J., Horvath, B. J., Brosnan, J. T., \& Kopsell, D. A. (2016). Plant health characteristics of creeping bentgrass affected by strobilurin fungicide applications and turfgrass diseases. Crop Science, 56(2), 862-869. https://doi.org/10.2135/cropsci2015.07.0450

CAC (Codex Alimentarius Commission). (2016). Codex pesticides residues in food online database [DB/OL]. Retrieved from http://www.fao.org/fao-who-codexalimentarius/standards/pestres/en

Campillo, N., Iniesta, M. J., Vinas, P., \& Hernándezcórdoba, M. (2015). Assessment of strobilurin fungicides' content in soya-based drinks by liquid micro-extraction and liquid chromatography with tandem mass spectrometry. Food Additives and Contaminants Part A-Chemistry Analysis Control Exposure \& Risk Assessment, 32(12), 2039-2047. https://doi.org/10.1080/19440049.2015.1096966

Commission, E. (2007). Method validation and quality control procedures for pesticide residues analysis in food and feed (Documment No. SANCO/3131/2007, p. 31). Brussels, Belgium.

Debona, D., Nascimento, K. J. T., Gomes, J. G. O., Auciqueperez, C. E., \& Rodrigues, F. A. (2016). Physiological changes promoted by a strobilurin fungicide in the rice-Bipolaris oryzae interaction. Pesticide Biochemistry and Physiology, 130, 8-16. https://doi.org/10.1016/j.pestbp.2015.12.006

Debona, D., Rodrigues, F. A. (2016). A strobilurin fungicide relieves Bipolaris oryzae-induced oxidative stress in rice. Journal of Phytopathology, 164(9), 571-581. https://doi.org/10.1111/jph.12481

European Commission. (2016). EU legislation on MRLs [DB/OL]. Retrieved from https://ec.europa.eu/food/ plant/pesticides/max_residue_levels/eu_rules_en

Fan, Z. P., Hong, T. S., Liu, Z. Z., Li, J. N., \& Wen, T. (2010). Design and realization of remote monitoring system for soil moisture in citrus orchards. Transactions of the CSAE, 26(8), 205-210.

GB 2763-2016. (2017). National food safety standard-Maximum residue limits for pesticides in food. Beijing: Standards Press of China.

Guo, X., Wang, K., Chen, G. H., Wu, X., Di, L. L., \& Wang, Y. (2017). Determination of strobilurin fungicide residues in fruits and vegetables by nonaqueous micellar electrokinetic capillary chromatography with indirect laser-induced fluorescence. Electrophoresis, 38(16), 2004-2010. https://doi.org/10.1002/elps. 201700060

Kanetis, L., Forster, H., \& Adaskaveg, J. E. (2007). Comparative efficacy of the new postharvest fungicides azoxystrobin, fludioxonil, and pyrimethanil for managing citrus green mold. Plant Disease, 91, 1502-1511. https://doi.org/10.1094/PDIS-91-11-1502 
Kanetis, L., Forster, H., \& Adaskaveg, J. E. (2008). Optimizing efficacy of new postharvest fungicides and evaluation of sanitizing agents for managing citrus green mold. Plant Disease, 92, 261-269. https://doi.org/10.1094/PDIS-92-2-0261

Kanetis, L., Soto-Estrada, A., \& Adaskaveg, J. E. (2004). Baseline sensitivities of Penicillium digitatum populations to azoxystrobin, fludioxonil and pyrimethanil. Phytopathology, 94, S49.

Kolosova, A., Maximova, K., Eremin, S. A., Zherdev, A. V., Mercader, J. V., Abad-Fuentes, A., \& Dzantiev, B. B. (2017). Fluorescence polarisation immunoassays for strobilurin fungicides kresoxim-methyl, trifloxystrobin and picoxystrobin. Talanta, 162, 495-504. https://doi.org/10.1016/j.talanta.2016.10.063

Li, L., Li, M., Chi, H. W., Yang, J. C., Li, Z. N., \& Liu, C. L. (2016). Discovery of flufenoxystrobin: Novel fluorine-containing strobilurin fungicide and acaricide. Journal of Fluorine Chemistry, 185, 173-180. https://doi.org/10.1016/j.jfluchem.2016.03.013

Liu, L. D., \& Wu, R. Z. (2014). Effect of different preservatives on the prevention and control of postharvest diseases of citrus. Academic Periodical of Farm Products Processing, 9, 27-30.

Liu, X. P., Wang, J. Y., Gou, P., Mao, C. G., Zhu, Z. R., \& Li, H. Y. (2007). In vitro inhibition of postharvest pathogens of fruit and control of gray mold of strawberry and green mold of citrus by aureobasidin A. International Journal of Food Microbiology, 119, 223-229. https://doi.org/10.1016/j.ijfoodmicro.2007. 07.054

Lu, G. H., Chu, H. B., Chen, M., \& Yang, C. L. (2015). Synthesis and bioactivity of novel strobilurin derivatives containing the pyrrolidine-2,4-dione moiety. Chinese Chemical Letters, 15, 17-25. https://doi.org/10.1016/ j.postharvbio.2015.03.006

Ma, Q. L., Zhu, L. H., Feng, S. Y., Xu, R. W., Kong, D. X., Deng, X. X., \& Cheng, Y. J. (2015). Fluroxypyr-a potential surrogate of 2,4-dichlorophenoxyacetic acid for retarding calyx senescence in postharvest citrus fruit. Postharvest Biology and Technology, 105, 17-25.

Mahoney, K. J., \& Gillard, C. L. (2014). Plant health and yield of dry bean not affected by strobilurin fungicides under disease-free or simulated hail conditions. Canadian Journal of Plant Science, 94(8), 1385-1389. https://doi.org/10.4141/cjps-2014-159

Marin, A., Oliva, J., Garcia, C., Navarro, S., \& Barba, A. (2003). Dissipation rates of cyprodinil and fludioxonil in lettuce and table grape in the field and undercold storage conditions. Journal of Agricultural and Food Chemistry, 51(16), 4708-4711. https://doi.org/10.1021/jf021222e

Ochoa-Acuna, H. G., Bialkowski, W., Yale, G., \& Hahn, L. (2009). Toxicity of soybean rust fungicides to freshwater algae and Daphnia magna. Ecotoxicology, 18, 440-446. https://doi.org/10.1007/s10646-0090298-1

Raina-Fulton, R. (2015). Determination of neonicotinoid insecticides and strobilurin fungicides in particle phase atmospheric samples by liquid chromatography-tandem mass spectrometry. Journal of Agricultural and Food Chemistry, 63(21), 5152-5162. https://doi.org/10.1021/acs.jafc.5b01347

Russell, P. E. (2005). A century of fungicide evolution. Journal of Agricultural Science, 143, 11-25. https://doi.org/10.1017/S0021859605004971

Schenck, F. J., \& Hobb, J. E. (2004). Evaluation of the quick, easy, cheap, effective rugged and safe (QuEchERS) approach to pesticide residue analysis. Enviromental Contamination and Toxicology, 73, 24-30. https://doi.org/10.1007/s00128-004-0388-y

Schirra, M., Cabras, P., Angioni, A., \& Brandolini, V. (2002). Residue levels and storage decay control in Cv Star Ruby grapefruit after dip treatments with azoxystrobin. Journal of Agricultural and Food Chemistry, 50, 1461-1464. https://doi.org/10.1021/jf0112567

Sholberg, P. L., Bedford, K., \& Stokes, S. (2005). Sensitivity of Penicillium spp. and Botrytis cinerea to pyrimethanil and its control of blue and gray mold on stored apples. Crop Protection, 24, 127-134. https://doi.org/10.1016/j.cropro.2004.07.011

Wang, K., Chen, G. H., Wu, X., Shi, J., \& Guo, D. S. (2014). Determination of strobilurin fungicide residues in fruits and vegetables by micellar electrokinetic capillary chromatography with Sweeping. Journal of Chromatographic Science, 52, 157-163. https://doi.org/10.1093/chromsci/bmt001 
Woodward, J. E., Dodds, D. M., Main, C. L., Barber, L. T., Boman, R. K., Whitaker, J. R., ... Allen, T. W. (2016). Evaluation of foliar applications of strobilurin fungicides in cotton across the Southern United States. Journal of Cotton Science, 20(2), 116-124.

Wu, P., Wu, W. Z., Han, Z. H., \& Yang, H. (2016). Desorption and mobilization of three strobilurin fungicides in three types of soil. Environmental Monitoring and Assessment, 188(6), 363. https://doi.org/10.1007/ s10661-016-5372-6

Xie, Y. Q., Huang, Z. L., Yan, H. D., Li, J., Ye, L. Y., Che, L. M., \& Tu, S. (2015). Design, synthesis, and biological activity of oxime ether strobilurin derivatives containing indole moiety as novel fungicide. Chemical Biology \& Drug Design, 85(6), 743-755. https://doi.org/10.1111/cbdd.12460

Xue, J. Y., Li, H. C., Liu, F. M., Jiang, W. Q., \& Chen, X. C. (2014). Determination of strobilurin fungicides in cotton seed by combination of acetonitrile extraction and dispersive liquid-liquid microextraction coupled with gas chromatography. Journal of Separation Science, 37, 845-852. https://doi.org/10.1002/jssc. 201301223

You, X. W., Peng, W., Liu, F. M., Shi, K., \& Li, Y. (2015). Simultaneous determination of five strobilurin fungicides and the metabolite BF-500-3 in cereals, fruits and vegetables. International Journal of Environmental Analytical Chemistry, 95(11), 989-1000. https://doi.org/10.1080/03067319.2015.1077516

Zhao, J. H., Wang, L. K., Cheng, J. L., Wang, W., \& Ye, Q. F. (2017). Fate characterization of benzene kresoxim-methyl (a strobilurin fungicide) in different aerobic soils. Journal of Environmental Quality, 46(3), 546-552. https://doi.org/10.2134/jeq2016.08.0288

\section{Copyrights}

Copyright for this article is retained by the author (s), with first publication rights granted to the journal.

This is an open-access article distributed under the terms and conditions of the Creative Commons Attribution license (http://creativecommons.org/licenses/by/4.0/). 